\title{
Problem-based activities as a tool to develop cross-cultural competency at the foreign language classes
}

\author{
Victoriya Sibul ${ }^{1, *}$ \\ ${ }^{1}$ RUDN University (People's Friendship University of Russia), 117198, Moscow, Miklukho-Maklaya \\ str.6, Russia
}

\begin{abstract}
The article is devoted to applications of problem-based learning. Teaching foreign language is aimed nowadays at developing various skills to communicate with a speaker of another language as with a representative of a different culture, in other words, developing crosscultural competency. Cross-cultural communication, especially in business, may imply various problems and challenges so in foreign language classes it is necessary to reveal them and teach students how to deal with them most efficiently. Therefore, most teachers of foreign language try to incorporate problem-based approach in their classes. The choice of teaching material for connected with solving a problem tasks should be made with reference to applied problem-solving methods, intellectual level of students, and level of their critical and creative thinking. Problematisation can be based both on socio-linguistic materials and on professionally oriented assignments, in the form of case studies or specialized texts discussions in accordance with other teaching tasks. The article describes an experience of using problem-based technique in foreign language classes for students of Economic Faculty taking a course of "Foreign language for professional communication" as a way to develop skills helping to solve a variety of professionally oriented communicative tasks.
\end{abstract}

\section{Introduction}

The demand of modern employers for a specialist who is not just knowledgeable in the particular sphere but also has skill to properly apply acquired knowledge completing everyday practical job duties made us think about reorganising teaching process at foreign language classes. After careful study of modern trends in teaching methods, we decided in favour of problem-based learning. Due to high relevance of cross-cultural competency formation, we consider above-mentioned approach to teaching at foreign language classes as a prospective one as it allows us to rely on students' knowledge and skills acquired at classes on special subjects. Moreover, applying this approach we can use forms, tools and methods of teaching that alongside teaching foreign language help to form a future specialist. [1]

\footnotetext{
${ }^{*}$ Corresponding author: semenov.venture@mail.ru
} 
H. Barrows defines the following features of this method that we found the most matching to our task:

it is focused on a personality of a student;

particular problem is in the center of a teaching process;

it is aimed at working in small groups with a teacher as a facilitator. [2]

Developing class activities based on this approach, we followed commonly accepted three levels of problem-based learning method: theory, pattern, and practice. [3]

The key to proper application of problem-based learning is to engage learners in such a way that they find the learning process as natural as solving practical problems in their dayto-day professional life. Unlike every-day problem solving, doing such kind of an activity in class also requires learners to become conscious and critical of the process that they are going through. Assuming learners begin with a functioning level of foreign language, comfort with the learning environment and a reasonable level of motivation, the facilitation of a particular problem-based activity starts with the introduction of a relevant problem. It is important that the problem be carefully selected and communicated in such a way that learners will likely find it motivating, exciting or even challenging. The objective of problem introduction, also known as a trigger, is to encourage the feeling that a learner (or a group of students) needs to resolve the problem. Some common triggers include documentary films, newspaper clippings, field trips or presentations from people working in the field. [4]

Having proper interest in the subject, learners will begin to move away from seeing a teacher as an 'expert,' and will instead start constructing their own base of knowledge such as evidence of the problem, facts and figures, and yet to be tested solutions. Without a formal set of learning objectives or discipline centred base of knowledge offered to accumulate, students can develop algorithm of dealing with information they find and a consolidated personal base of knowledge for future action [5].

\section{Materials and methods}

\subsection{Participants}

Problem-based activities were offered to students of Economic Faculty of our RUDN University who were taking a supplementary course of "Foreign language for professional communication and specialized translation". They were applied at classes on practical use of foreign language for professional communication and specialised translation practice.

\subsection{Materials for problem-based activities}

Business English materials used at foreign language classes should integrate the English language and business content. According to Ponomarenko E.V. and Malyuga E. [6], a successful integration of language and content in a classroom should explicitly integrate language goals and professional skill training goals and provide opportunities for both language development and professional growth. It is believed that language proficiency and professional knowledge should be developed simultaneously within Higher Education. The focus of the foreign language classroom should be on meaningful input, such as academic content connected with special subjects aimed to develop professional skills. The modification of the target language facilitates language acquisition and makes academic content accessible to foreign language learners. Integrated language and professional skill training offers a means by which learners can continue their academic or cognitive development, while they are also developing their language proficiency, with the adapted 
functional linguistics elements being very helpful to that end [7]. Thus, choosing materials for our problem-based class activities we always tried to correlate them to the economic topics that our students study within their basic professional courses. Here we cooperate with our colleagues from other departments of the faculty implementing idea of interdisciplinary approach. We try to apply sources recommended by specialists in business and economic sphere because they provide up-to-date information and data that can be helpful for a young specialist with the desire to develop professional knowledge. Among most often used we can mention "New York Times" newspaper, "The Economist" journal (both printed and on-line versions), Bloomberg web-site https://www.bloomberg.com/, Advertising and Marketing news web-site http://adage.com/, web-site for entrepreneurs https://www.entrepreneur.com/topic/management and, of course, news from leading broadcasters like BBC and $\mathrm{CNN}$, their business divisions. It helps to provide our students with up-to-date information on what is going on in sphere of their speciality and get them acquainted with various views on current issues. On-line resources also provide us with the opportunity to use different channels of information: students can both read some materials in a text format and also watch a video or listen to audio materials on the same topic. It is a great opportunity to rely on different types of memory.

\subsection{Stages of teaching process based on problem-based learning approach}

There is no unified model of problem-based leaning, but at the same time, it is also unhelpful to suggest that teachers begin the process without some basic scheme or algorithm of applying the technique. [5]

The following model provides a starting point that we took as a pattern and then adapt to suit a particular activity, module within our program:

Step 1 - Identify and clarify unfamiliar terms presented in the scenario (article, video interview, blog on professional web-sites); note down those that remain unexplained after discussion for further autonomous work with them by students

Step 2 - Define the problem or problems to be discussed; students may present different views on the issues, but all should be considered; note down a list of agreed problems concerned presented material on the blackboard. Try to check that problems are formulated clearly, and all students of the group understand the nature of the problem.

Step 3 - "Brainstorming" session to discuss the problem(s), suggesting possible explanations on the basis of prior knowledge; students draw on each other's knowledge and identify areas of incomplete knowledge; note down results of the whole discussion on the blackboard. Make sure that you listed all suggested points

Step 4 - Review steps 2 and 3 and arrange explanations into tentative solutions; note down and organise the explanations and restructures if necessary

Step 5 - Formulate learning objectives; group reaches consensus on the learning objectives; teacher ensures learning objectives are focused, achievable, comprehensive, and appropriate

Step 6 - Individual study during which all students gather information related to each learning objective. It may result in a presentation, report case analyses.

Step 7-Group shares results of individual study with all students identify their learning resources and share their results; tutor checks learning and may assess the group.

\subsection{Role of a teacher}

The Teacher:

- identifies a problem that is purposely complex and vague yet intriguing enough to excite learners to inquire about it, do research on it and draw reasonable multiple solutions 
or conclusions on the problem. The problem should be linked to their basic professional course content. At the same time, it should help teach learners new skills they will use for a problem that would be too difficult for them to complete on their own. In our classes problem is usually introduced in a form of a written articles, blogs, audio or video format that include details about its background but do not provide too much information make sure that learners could find some more information on their own as they search for a solution.

- organizes learners in groups that represent different skill levels and diversity in an effort to achieve more successful team dynamics and outcomes and finds ways to engage learners to collaborate in a team. This can be achieved by having students identify their strengths and weaknesses which will assist them as they assume different roles during the problem-solving process.

- provides instructional support to assist the learners in forming their understanding of new content and the problem-solving process. Support should be provided from the time teacher presents the problem to when the teams present their solutions. Teacher should always mind that hisher role will be facilitator, coach and mentor to guide and move students from what they already know to a deeper understanding of new material.

\subsection{Role of a Learner}

During problem-based learning, learners collaborate in small teams to explore the introduced problem situation. Through this exploration learners are expected to examine gaps in their own knowledge and skills in order to decide what information they need to acquire in order to resolve or manage" the problem situation [5]. What follows is a method that summarizes the steps students take to solve the problem situation which is excerpted from and used with permission $[8,9]$ :

The Learner:

- explores the issues related to the problem: reads, discusses and analyses the problem identifying its significant parts.

- lists what his her team knows about the problem: discusses with team members current knowledge and experiences that relate to the problem; identifies the strengths and capabilities of each team member; and finally comes out with possible solutions and accept contributions of other team members.

- develops and writes out the problem statement in his her own words: this description should be based on what learner knows about the problem and what helshe will need to know to solve the problem.

- lists all possible solutions to the problem that may be ideas, speculations, and hypotheses about the problem. Learners should be instructed to order them from the most likely to the least likely and choose the one his her team feels is most likely to succeed.

- lists actions to be taken with a time schedule that can be done answering following questions:

a. What do we have to know and do to solve the problem?

b. How do we rank these actions?

c. How do these actions relate to our list of possible solutions?

d. Do we agree on these actions and if not, how do we reach consensus?

- lists what his questions: "What do we need to know to solve this problem?" or "Can the instructor provide us with more information?"; also the team needs to discuss possible resources to solve the problem such as the Internet, textbooks, primary and secondary sources, interviews, an instructor. 
- writes his ไher team's report or an essay with the solution to the problem that includes supporting documents or prepares a presentation of a team's offer to problem solution: typically, each team offers their solutions as a group presentation to the entire class and the content o presentation should include the problem statement, questions, gathered data, analysis of the data, and support for solutions or recommendations based on the data analysis.

- presents and defends teams conclusions together with the foundation upon which they are drawn. Learners should be instructed to do the following:

a. State both the original problem and team's conclusions

b. Summarize the process in which the problem was solved that means to present options originally considered, difficulties encountered and resources used.

c. Convince other teams of your solution by using supporting proper argumentation, reliable data and sources.

d. Clearly address and or answer any questions and comments of other teams taking part in constructive discussion.

- reviews and reflects on his her individual and team's performance. This reflection is an important step helps to apply what was learned and how learner could improve on the process. A key component of problem-based learning is understanding by learners that they have a need to apply what they have learned in other situations (transfer of knowledge), how to apply what they have learned in their personal lives (as students and citizens of a community) and how to apply what they have learned in another course-related projects. Such reflective thinking according to J. Barell, also helps students become more observant of their own learning environment and to pose thoughtful questions as they solve problems [10].

\section{Results}

We considered results of applying problem-based approach at foreign language classes in terms of various aspects: academic results at the end of the term, assessment made by future employers during students' internship (work-placement), opinion of students expressed during the survey.

Firstly, students' end of term assessment showed that about $70 \%$ of students significantly improved their general command of foreign language and skills to apply it in professional communication.

Table 1. Students end of term results.

\begin{tabular}{|c|c|c|c|}
\hline $\mathrm{N}$ & Grade & $\begin{array}{c}\% \text { in the term before } \\
\text { application of problem- } \\
\text { based activities }\end{array}$ & $\begin{array}{c}\% \text { in the term after } \\
\text { application pf } \\
\text { problem-based } \\
\text { activities }\end{array}$ \\
\hline 1 & $\mathrm{~A} \mathrm{(5+)}$ & $15 \%$ & $20 \%$ \\
\hline 2 & $\mathrm{~B}(5)$ & $20 \%$ & $35 \%$ \\
\hline 3 & $\mathrm{C}(4)$ & $30 \%$ & $35 \%$ \\
\hline 4 & $\mathrm{D}(3+)$ & $20 \%$ & $5 \%$ \\
\hline 5 & $\mathrm{E} \mathrm{(3)}$ & $15 \%$ & $5 \%$ \\
\hline
\end{tabular}

We assume it was due to increase in motivation to study foreign language as classes became closer to their future profession and application of received knowledge and skills became more obvious for the student.

Secondly, responses from the companies where students did their professional internship/work-placement were more positive in their assessment regarding their level of professional competency, including communication in foreign language both with 
colleagues and with customers. Such responses demonstrate that approach meets needs of prospective employers of our students and increase chances for our students to get better job.

Thirdly, we conducted a survey among students asking them to assess efficiency and significance of including problem-based activities in foreign language classes. The survey showed that $75 \%$ of students found such activities as highly efficient and significant, $15 \%$ saw no rational for doing such activities in foreign language classes and $10 \%$ were undecided. High rate of students satisfaction proves that they were really involved in a teaching process.

Regarding learning strategies, we found that our problem-based activities enhanced students' use of elaboration strategies, critical thinking, metacognitive self-regulation, effort regulation, and peer learning. Moreover, the above-mentioned improvements are observed not only at foreign language classes, but at classes on special subjects as well according to comments from our colleagues teaching other subjects within obligatory curriculum.

\section{Conclusions}

To sum it up, the experience of applying problem-based activities in foreign language classes for students of non-linguistic speciality (in particular economic one) proved that such teaching approach is relevant and has some potential to enhance level of motivation among non-linguistic students to study foreign language, to improve their competency in applying foreign language knowledge to complete daily professional tasks and thus increases their compatibility on labour market.

Moreover, it should be noted, that problem-based approach allows individuals relying on various information and data to work out own principles and position regarding professional issues and after matching them to others gain personal worldview. Problembased learning has much to offer in foreign language classes of Higher Schools. As a teaching approach, it has both linguistic benefits, as shown in the research on the role of natural, meaning-focused classroom interaction in language learning, and affective benefits in the form of boosting student motivation and encouraging learner autonomy in learning outside the classroom. [11]

However, to achieve these benefits, teachers and educational management must ensure that students understand the principles lying behind problem-based learning and recognize that they are participating in an effective learning process, even if it is unfamiliar to them. Thus, introduction of problem-based approach can significantly enhance quality of knowledge and skills of students, but at the same time it proved to be rather complicated and requiring high professionalism and additional efforts from teachers.

\section{References:}

1. E.N. Malyuga, A. Krouglov, B. Tomalin, Linguo-cultural competence as a cornerstone of translators' performance in the domain of intercultural business communication, XLinguae, A European Scientific Language Journal 2, 566-582 (2018) http://www.xlinguae.eu/2018_11_02_46.html, DOI: 10.18355/XL.2018.11.02.46

2. H. Barrows, Problem-based learning: An approach to medical education. Springer series on Medical Education, New York, (1980)

3. E. Graaf, A. Kolmos, Characteristics of problembased learning, Int J. Engng Ed. 19, 15, 657-663 (2003) 
4. J. Farley, J. Erickson, H. Daly, Ecological Economics: A Workbook For ProblemBased Learning, London: Island Press, (2007)

5. M. Savin-Baden, Facilitating Problem-based Learning: Illuminating Perspectives, Maidenhead: Open University Press (2003)

6. E.V. Ponomarenko, E. Malyuga, Business English and functional linguistics: teaching practical English in perfect harmony with theory, ICERI2012: 5th International Conference of Education, Research and Innovation. Conference Proceedings, Madrid: IATED, 4524-4529 (2012)

7. E.V. Ponomarenko, O.V. Magirovskaya, S.N. Orlova, Introduction: Professional Discourse in the Focus of Functional Linguistics, In: E. Malyuga (ed.), Functional Approach to Professional Discourse Exploration in Linguistics, Springer, Singapore, 120 (2020) DOI: https://doi.org/10.1007/978-981-32-9103-4_1

8. Stanford University Newsletter, Speaking of Teaching. Problem-Based Learning. Center for Teaching and Learning Web site: http://www.stanford.edu/dept/CTL/Newsletter/problem_based_learning.pdf. (2001)

9. J. Landsberger, Problem-based learning http://www.studygs.net/pbl.htm (2011)

10. J. Barell, Problem-based learning: An inquiry approach. (2nd ed.). Thousand Oaks, CA: Corwin Press, Inc. (2007)

11. B. Alan, F. L. Stoller, Maximizing the benefits of project work in foreign language classrooms, English Teaching Forum 43(4), 10-21 (2005) 